\title{
Tuberculosis-Associated Immune Reconstitution Inflammatory Syndrome Manifested As Multiple Central Nervous System Granulomas In Non-HIV Patient: A Case Report
}

\section{Can-Hong YANG}

The Third Affiliated Hospital of Southern Medical University

\section{Qing-Gan Zeng}

The Third Affiliated Hospital of Southern Medical University

Tian-Ming Lü ( $\square$ lutianming@139.com)

The Third Affiliated Hospital of Southern Medical University https://orcid.org/0000-0003-0747-4228

\section{Case report}

Keywords: microorganisms, tuberculosis, patient, nervous

Posted Date: October 18th, 2021

DOl: https://doi.org/10.21203/rs.3.rs-963657/v1

License: (c) (i) This work is licensed under a Creative Commons Attribution 4.0 International License.

Read Full License 


\section{Abstract}

Background: In addition to developed in HIV patient during highly active antiretroviral therapy, immune reconstitution inflammatory syndrome (IRIS) has also been well recognized in non-HIV immunocompromised patients induced by latent viruses, untreated microorganisms, or treating microorganisms. Mycobacteria tuberculosis is one of the most common pathogens inducing IRIS.

Case presentation: Here, we report a tuberculosis patient progressed with IRIS that additional central nervous system (CNS) granuloma occurred during the anti-tuberculosis treatment (ATT) process with her pulmonary symptoms improved after quadruple anti-tuberculosis. This case highlights the need to increase the awareness of IRIS in non-HIV immunocompromised patients.

Conclusions: TB-IRIS must be considered when the condition deteriorates or development of new lesions at distant sites in the course of ATT. Early identification and diagnosis help to handle timely and correctly.

\section{Background}

Immune reconstitution inflammatory syndrome (IRIS) refers to a phenomenon that clinical manifestation become exacerbated or diseases developed in HIV patient during highly active antiretroviral therapy when the immune response recovers with the restoration of CD 4 count. However, IRIS has also been well recognized in non-HIV immunocompromised patients after organ transplantation, recipients of tumor necrosis factor antagonist or neutropenic patients ${ }^{[1]}$. Besides, immune suppressed condition can also be induced by latent viruses, untreated microorganisms, or treating microorganisms ${ }^{[1]}$. Mycobacteria tuberculosis is one of the most common pathogens inducing IRIS ${ }^{[2]}$. In non-HIV patients, Tuberculosisassociated IRIS (TB-IRIS) can present with a variety of clinic-radiological presentations that are not easy to distinguish from drug resistance and treatment failure ${ }^{[2]}$, the awareness of IRIS in non-HIV immunocompromised patients need to be increased.

Here, we report a tuberculosis patient progressed with IRIS that additional central nervous system (CNS) granuloma occurred during the anti-tuberculosis treatment (ATT) process with her pulmonary symptoms improved after quadruple anti-tuberculosis.

\section{Case Presentation}

A 20-year-old girl suffered from painless lumps in her left neck in 2016-10. The lump progressed in lower jaws and the size increased gradually. In 2017-09, she was diagnosed of tuberculosis with multiple sputum smears test of Mycobacterium tuberculosis and treated with quadruple ATT of rifampicin, isoniazid, pyrazinamide and ethambutol. Her pulmonary symptoms improved, but from 2018-02, she had headache with dysuria, weakness and numbness of lower limbs, no fever, chills, jet vomiting, hemoptysis, unconsciousness and speech disturbance. Muscle strength of bilateral upper limbs was grade 5 , while 
grade 3 in bilateral lower limbs with decreased muscle tension and hyper-active tendon reflexes. Bilateral Babinski signs were positive. The sensation below level of the lower end of the sword was disturbed. Repeated sputum smears and cultures, and cerebrospinal fluid (CSF) smears, culture and PCR test of Mycobacterium tuberculosis were negative. Erythrocyte sedimentation rate, soluble interleukin II receptor, angiotensin-converting enzyme and other laboratory examinations produced unremarkable findings. MR scan showed multiple space-occupying lesions in right frontal gyrus, right anterior of pontine, suprasaddle and in the spinal cord of T3, T5 and T6 vertebral level (Fig. 1). Space-occupying lesion resection was performed to relieve spinal cord compression and confirmed to be inflammatory granulomatous (Fig. 1). IRIS was diagnosed. On 2018-04-19 and 2018-05-16, two courses of methylprednisolone (1000 $\mathrm{mg}, \mathrm{VD}, \mathrm{qd}$ ) was applied for 5 days and decreased gradually. Muscle strength in bilateral lower limbs improved gradually to grade 4+ and the urine function returned to normal. After discharge, prednisone (12mg, p.o., qd) was treated for 3 months along with ATT with rifampicin and isoniazid. Follow up was performed in 2018-09 and 2019-03, she could walk normally, CSF tests and MR scan results also improved obviously (Fig. 1, Tab.1).

\section{Tab.1 Manifestation and CSF examination during the course of disease}

\begin{tabular}{|c|c|c|c|c|}
\hline Date & & Apr-18 & Sep-18 & Mar-19 \\
\hline \multirow[t]{3}{*}{ Manifestation } & Muscle tension & Decreased & Increased & Normal \\
\hline & $\begin{array}{l}\text { Muscle Strength of Both Lower } \\
\text { Limbs }\end{array}$ & Grade 3 & Grade 4+ & $\begin{array}{l}\text { Grade } \\
5\end{array}$ \\
\hline & Urine function & $\begin{array}{l}\text { Urinary } \\
\text { retention }\end{array}$ & Normal & Normal \\
\hline \multirow{7}{*}{$\begin{array}{l}\text { CSF } \\
\text { examination }\end{array}$} & Pressure $\left(\mathrm{mmH}_{2} 0\right)$ & 205 & 150 & 155 \\
\hline & $\operatorname{Protein}(\mathrm{mg} / \mathrm{L})$ & 4471.1 & 1205.5 & 923.2 \\
\hline & Glucose(mmol/L) & 2.1 & 2.6 & 2.85 \\
\hline & Chloride (mmol/L) & 119.1 & 122.1 & 125.9 \\
\hline & Pandy test & ++ & + & \pm \\
\hline & White blood cell count $\left({ }^{*} 10^{\wedge} 6 / \mathrm{L}\right)$ & 4 & 3 & 1 \\
\hline & Acid-fast stain & - & - & - \\
\hline
\end{tabular}

\section{Discussion And Conclusions}

Typically, IRIS usually developed in HIV patient during highly active antiretroviral therapy. However, IRIS has also been well recognized in non-HIV immunocompromised patients induced by latent viruses, 
untreated microorganisms, or treating microorganisms ${ }^{[1]}$. Mycobacteria tuberculosis is one of the most common pathogens inducing IRIS ${ }^{[2]}$. The prevalence of TB-IRIS is still unclear and is estimated $2 \%-23 \%$ in non-HIV patients in a few studies ${ }^{[2]}$. It may occur during or even after completion of ATT ${ }^{[3]}$ and represents an adverse clinical consequence of the restoration of immunity in the patient suffering from a serious systemic infection. TB-IRIS patients may experience development of new tuberculous lesions or paradoxical worsening of pre-existing tuberculous lesions despite on effective ATT ${ }^{[3]}$, such as initial or worsening radiological features of TB, initial or enlarging lymph nodes, initial or worsening serositis, initial or worsening CNS, other tissue involvement or cold, abscesse ${ }^{[2,4]}$. However, new neurological lesion as the paradoxical reaction of TB-IRIS is uncommon, especially in patients with drug resistant tuberculosis ${ }^{[5]}$.

However, the diagnostic criteria and guidelines of IRIS in non-HIV patients have not been established. Some authors proposed draft diagnostic criteria according to the clinical courses of in $\square$ ammatory disorders of various organs triggered by pre-existing antigens and pathogenic microorganisms ${ }^{[1]}$. Glucocorticoids, tumor necrosis factor inhibitors or anti-IL-6 antibodies, and statins are the commonly used agents for non-HIV IRIS patient ${ }^{[1]}$. For TB-IRIS, although some patients improve spontaneously with continuation of ATT regimens in a few weeks, glucocorticoids are required with condition deteriorates ${ }^{[6-}$ 8].

In this case, the CNS granuloma occurred during the ATT with pulmonary symptoms improved. Results of CSF examination of tuberculosis by various methods were negative, the lesion in the spinal cord did not show caseous necrosis and Langerhans cells, but infiltrated with a large number of acute and chronic inflammation cells including CD4 (+) lymphocytes. Eventually, she was cured after systematic approach of corticosteroid therapy. In addition, there was no TB drug resistance, no drug toxicity or reaction, no another opportunistic infection or neoplasm. Therefore, TB-IRIS should be considered.

In short, in the course of ATT, once the condition deteriorates or development of new lesions at distant sites, after excluding new opportunistic infections or drug tolerance, malabsorption and drug reactions, TB-IRIS must also be considered. Early identification and diagnosis help to handle timely and correctly.

\section{Abbreviations}

IRIS: Immune reconstitution inflammatory syndrome;

TB-IRIS: Tuberculosis-associated immune reconstitution inflammatory syndrome;

CNS: central nervous system;

ATT囚anti-tuberculosis treatment》

CSF: cerebrospinal fluid. 


\section{Declarations}

Acknowledgements

We are thankful to the patient for the support given in providing the data.

\section{Authors' contributions}

C-HY analyzed and interpreted the data and wrote the manuscript. Q-GZ analyzed and interpreted the data, and revised the manuscript. T-ML designed and conceptualized the study, interpreted the data, and revised the manuscript.

\section{Funding}

This work was supported by grants from Natural Science Foundation of Guangdong Province (2021A1515010006 and 2020A1515110506).

\section{Ethics approval and consent to participate}

This study followed the tenets of the Declaration of Helsinki and was approved by the Medical Ethics Committee of the Third Affiliated Hospital of Southern Medical University (2021-怄-020). Informed consent was obtained from the participant included in the study.

\section{Consent for publication}

Written informed consent was obtained from the patient for publication of this case report and any accompanying images.

\section{Competing interests}

The authors declare that they have no competing interests.

\section{Availability of data and materials}

Data sharing is not applicable to this article as no datasets were generated or analyzed during the current study.

\section{Author details}

Department of Neurology, the Third Affiliated Hospital of Southern Medical University, Guangzhou 510630, P. R. China

*Corresponding author: Tianming Lü, Department of Neurology, the Third Affiliated Hospital of Southern Medical University, No. 183, Zhongshan Road West, Guangzhou 510630, P. R. China. Fax: 86-2062784371. Tel: 86-20-62784371. E-mail: lutianming@139.com 


\section{References}

1. Sueki H, Mizukawa Y, Aoyama Y. Immune reconstitution inflammatory syndrome in non-HIV immunosuppressed patients[J]. J Dermatol. 2018;45(1):3-9.

2. Aggarwal D, Bhardwaj M, Kumar A, Saini V, Sawal N. Immune reconstitution inflammatory syndrome in non-HIV patients with tuberculosis. A case series[J]. Indian J Tuberc. 2020;67(1):143-7.

3. Geri G, Passeron A, Heym B, Arlet JB, Pouchot J, Capron L, Ranque B. Paradoxical reactions during treatment of tuberculosis with extrapulmonary manifestations in HIV-negative patients[J]. Infection,2013,41(2):537-543.

4. Suryana K. A Challenge in Diagnosis of Tuberculosis-Associated Immune Reconstitution Inflammatory Syndrome (TB-IRIS) [J]. HIV AIDS (Auckl),2020,12:263-269.

5. Pepper DJ, Marais S, Maartens G, Rebe K, Morroni C, Rangaka MX, Oni T, Wilkinson RJ, Meintjes G. Neurologic manifestations of paradoxical tuberculosis-associated immune reconstitution inflammatory syndrome: a case series[J]. Clin Infect Dis,2009,48(11):e96-e107.

6. Hawkey CR, Yap T, Pereira J, Moore DA, Davidson RN, Pasvol G, Kon OM, Wall RA, Wilkinson RJ. Characterization and management of paradoxical upgrading reactions in HIV-uninfected patients with lymph node tuberculosis[J]. Clin Infect Dis. 2005;40(9):1368-71.

7. Lanzafame M, Vento S. Tuberculosis-immune reconstitution inflammatory syndrome[J]. J Clin Tuberc Other Mycobact Dis. 2016;3:6-9.

8. Meintjes G, Scriven J, Marais S. Management of the immune reconstitution inflammatory syndrome[J]. Curr HIV/AIDS Rep. 2012;9(3):238-50.

\section{Figures}



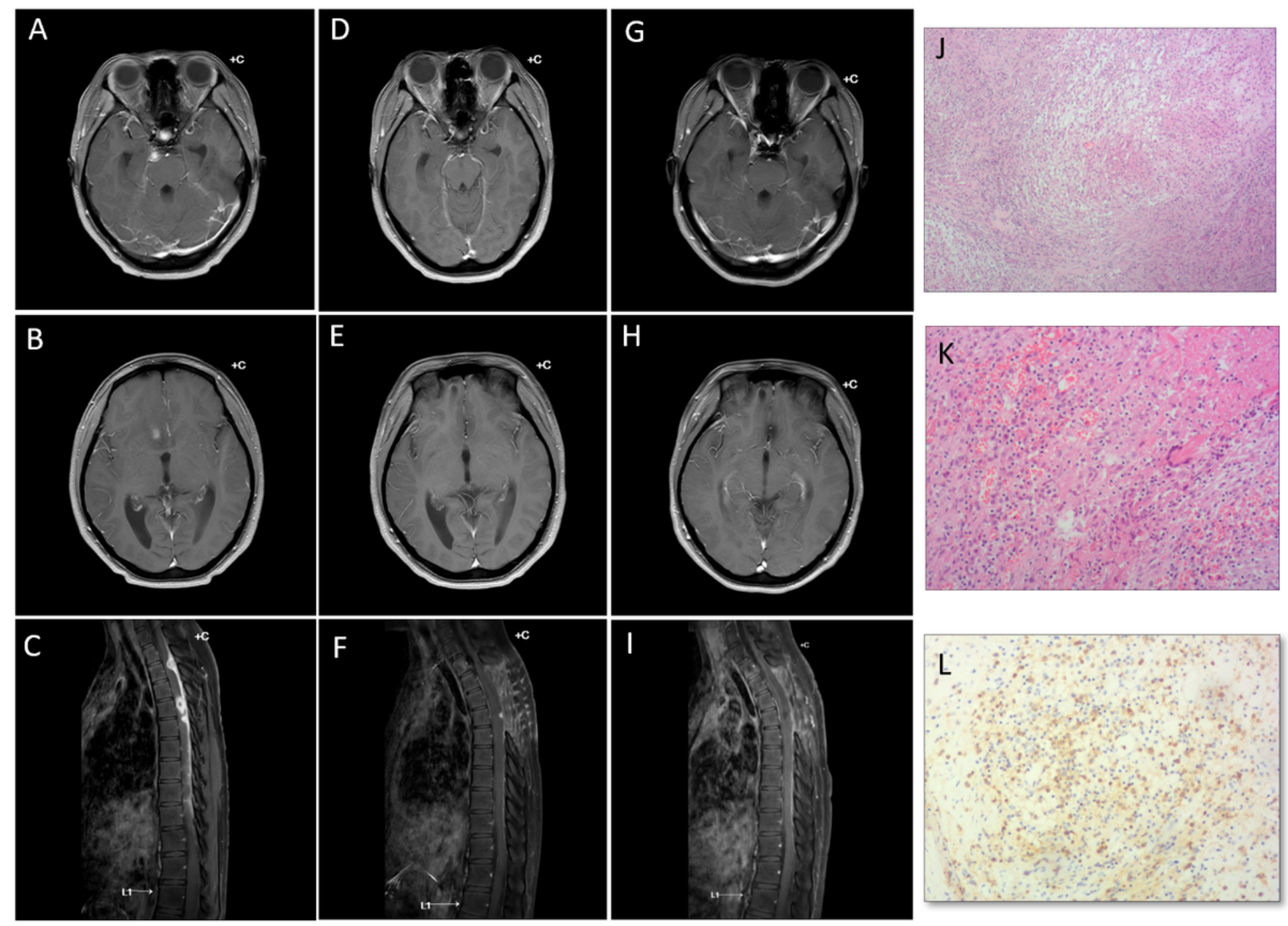

\section{Figure 1}

MR scan showed multiple space-occupying lesions in right anterior of pontine, suprasellar (A), right frontal gyrus (B) and in the spinal cord of T3, T5 and T6 vertebral level (C) in April 2018. The lesions improved after corticosteroid therapy in September 2018 (D-F) and in March 2019 (G-I). The lesion biopsy showed nodular locally, patchy necrosis was observed at the center of the nodule, fibrous tissue was observed in the peripheral with small vascular hyperplasia. Multiple acute, chronic cells infiltration and scattered polynuclear giant cells were also observed (J: HE 40x, K: HE 100x). CD4(+) (L, 100x) and CD68(+), PAS (-), CD1a(-), Langerin(-), S100(-) , acid stain (-) (not showed). 